\title{
Enhancing the ABAQUS Thermomechanics Code to Simulate Steady and Transient Fuel Rod Behavior
}

\section{Proceedings of Top Fuel 2009}

The INL is a

U.S. Department of Energy

National Laboratory

operated by

Battelle Energy Alliance

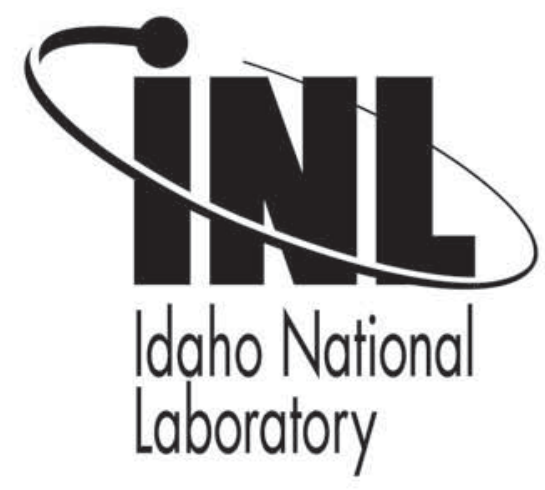

\author{
R. L. Williamson \\ D. A. Knoll
}

\section{September 2009}

This is a preprint of a paper intended for publication in a journal or proceedings. Since changes may be made before publication, this preprint should not be cited or reproduced without permission of the author. This document was prepared as an account of work sponsored by an agency of the United States Government. Neither the United States Government nor any agency thereof, or any of their employees, makes any warranty, expressed or implied, or assumes any legal liability or responsibility for any third party's use, or the results of such use, of any information, apparatus, product or process disclosed in this report, or represents that its use by such third party would not infringe privately owned rights. The views expressed in this paper are not necessarily those of the United States Government or the sponsoring agency. 


\title{
Enhancing the ABAQUS Thermomechanics Code to Simulate Steady and Transient Fuel Rod Behavior
}

\author{
R. L. Williamson and D. A. Knoll \\ Idaho National Laboratory \\ PO Box 1625, Idaho Falls, ID 83415-3855, USA \\ Tel:(208) 526-0576,Fax:(208) 526-2930,Email:Richard.Williamson@inl.gov
}

\begin{abstract}
A powerful multidimensional fuels performance capability, applicable to both steady and transient fuel behavior, is developed based on enhancements to the commercially available ABAQUS general-purpose thermomechanics code. Enhanced capabilities are described, including: $\mathrm{UO}_{2}$ temperature and burnup dependent thermal properties, solid and gaseous fission product swelling, fuel densification, fission gas release, cladding thermal and irradiation creep, cladding irradiation growth, gap heat transfer, and gap/plenum gas behavior during irradiation. The various modeling capabilities are demonstrated using a $2 D$ axisymmetric analysis of the upper section of a simplified multi-pellet fuel rod, during both steady and transient operation. Computational results demonstrate the importance of a multidimensional fully-coupled thermomechanics treatment. Interestingly, many of the inherent deficiencies in existing fuel performance codes (e.g., $1 D$ thermomechanics, loose thermo-mechanical coupling, separate steady and transient analysis, cumbersome pre- and postprocessing) are, in fact, ABAQUS strengths.
\end{abstract}

\section{INTRODUCTION}

Important aspects of fuel rod behavior, for example pellet-clad interaction (PCI), fuel fracture, and nonaxisymmetric cooling and oxide formation, are inherently multidimensional. Current fuel rod simulation codes typically approximate such behavior using a quasi $2 \mathrm{D}$ (or 1.5D) approach $^{1-3}$ and, often, separate codes must be used for steady and transient (or accident) conditions. Notable exceptions are the EPRI propriety code $\mathrm{FALCON}^{4}$ which is $2 \mathrm{D}$ and can be applied to steady or transient operation, and the French codes TOUTATIS ${ }^{5}$ and ALCYONE $^{6}$ which are 3D. Recent studies have indicated the need for multidimensional fuel rod simulation capability, particularly for accurate predictions of PCI. ${ }^{7}$

The Idaho National Laboratory (INL) is currently developing next-generation capability to model nuclear fuel rod performance. The goal is to develop a $2 \mathrm{D} / 3 \mathrm{D}$ computer code (BISON) which solves the fully coupled thermomechanics equations, includes multiphysics constitutive behavior for both fuel and cladding materials, is applicable to both steady and transient operation, and is designed for efficient use on parallel computers. ${ }^{8,9}$ To provide guidance and a prototyping environment for this effort, plus provide the INL with near-term multidimensional fuel modeling capability, the commercially available ABAQUS ${ }^{10}$ thermomechanics software has been enhanced to include the fuel behavior phenomena necessary to afford a practical fuel performance simulation capability. This paper details the enhancements which have been implemented in ABAQUS to date, and provides results of a multi-pellet fuel rod problem which demonstrates the new capability.

\section{CAPABILITY DEVELOPMENT}

\section{II.A. ABAQUS Framework}

ABAQUS provides a reasonable general framework for fuel performance modeling. The code employs modern finite element methods to solve the nonlinear thermomechanics equations in one, two, or threedimensions, using linear or quadratic elements. The temperature and displacement fields are solved in a fullycoupled fashion, using sophisticated iteration and time integration error control. The code includes robust contact algorithms, essential for computing multidimensional pellet-pellet or pellet-clad interaction. Extensive constitutive models are available, including isotropic and anisotropic elasticity, thermal expansion, plasticity, and thermal creep. Due to its commercial nature and widespread use, ABAQUS includes powerful pre- and 
post-processing software, facilitating efficient problem setup and rapid display and interpretation of results. The code undergoes extensive and well-documented verification and validation procedures, reducing the risk of coding errors leading to invalid results. Essential for the intended application, ABAQUS includes a user interface permitting the inclusion of user-developed models (via FORTRAN subroutines) to simulate fuel-specific phenomena. This powerful interface makes it possible to define any constitutive model of arbitrary complexity. Field variables can be defined to track important spatial and time-dependent fuel-specific phenomena, such as burnup and fission gas produced and trapped.

An obvious downside of using commercial software for fuels modeling is that one must work without full access to the source code. Experience to date with ABAQUS has shown that this can be cumbersome at times, but has not prevented inclusion of the important models needed to describe fuel behavior.

\section{II.B. Fuel Models}

Focusing initially on $\mathrm{UO}_{2}$ fuel, user subroutines have been developed and tested to describe temperature and burnup dependent thermal properties, solid and gaseous fission product swelling, densification, and fission gas release.

The temperature-dependent thermal conductivity of unirradiated $\mathrm{UO}_{2}$ is defined using an empirical equation suggested by Fink. ${ }^{11}$ This relationship is then modified to account for the effects of irradiation and porosity using a series of multipliers, as outlined in detail by Lucuta et al. ${ }^{12}$ Figure 1 illustrates the temperature and burnup dependent thermal conductivity based on this approach. A significant irradiation effect is evident, particularly at lower

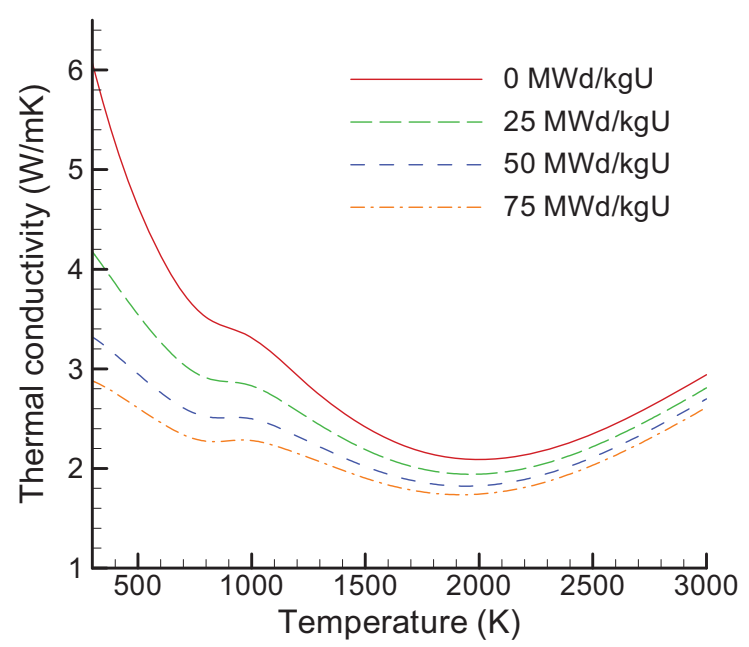

Figure $1 \mathrm{UO}_{2}$ thermal conductivity as a function of temperature and burnup. temperatures. Note that the bump in the curve at zero burnup results from radiation damage, which occurs rapidly at the beginning of irradiation and then saturates. ${ }^{12}$ As with the conductivity, an empirical relationship from Fink $^{11}$ is used to define the temperature-dependent specific heat. Within the same user subroutine, internal energy generation is computed from a prescribed fission density rate, which can be space- and time-dependent.

Swelling as a result of both solid and gaseous fission products is included using empirical relations from MATPRO. ${ }^{13}$ Solid fission product swelling is expressed as a simple linear function of burnup:

$$
\Delta \varepsilon_{s w-S}=6.407 \times 10^{-5} \rho \Delta B u
$$

where $\Delta \varepsilon_{\mathrm{sw}-\mathrm{s}}$ is the volumetric solid swelling increment, $\Delta \mathrm{Bu}$ the burnup increment (fissions/atoms-U), and $\rho$ is the density $\left(\mathrm{kg} / \mathrm{m}^{3}\right)$. Swelling due to gaseous fission products is approximated by a semi-empirical model:

$$
\begin{array}{r}
\Delta \varepsilon_{s w-g}=2.25 \times 10^{-31} \Delta B u \rho(2800-T)^{11.73} * \\
e^{-0.0162(2800-T)} e^{-0.021 \rho B u}
\end{array}
$$

where $\Delta \varepsilon_{\mathrm{sw}-\mathrm{g}}$ is the volumetric gas swelling increment, $\mathrm{Bu}$ and $\Delta \mathrm{Bu}$ are the burnup and burnup increment (fissions/atoms-U), respectively, $\rho$ is the density $\left(\mathrm{kg} / \mathrm{m}^{3}\right)$ and $\mathrm{T}$ is the temperature $(\mathrm{K})$. Figure 2 shows a plot of the gaseous and total fission product swelling as a function of temperature and burnup. The MATPRO ${ }^{13}$ correlations indicate that gaseous swelling does not become significant until above $1500 \mathrm{~K}$ and is saturated by a burnup of 20

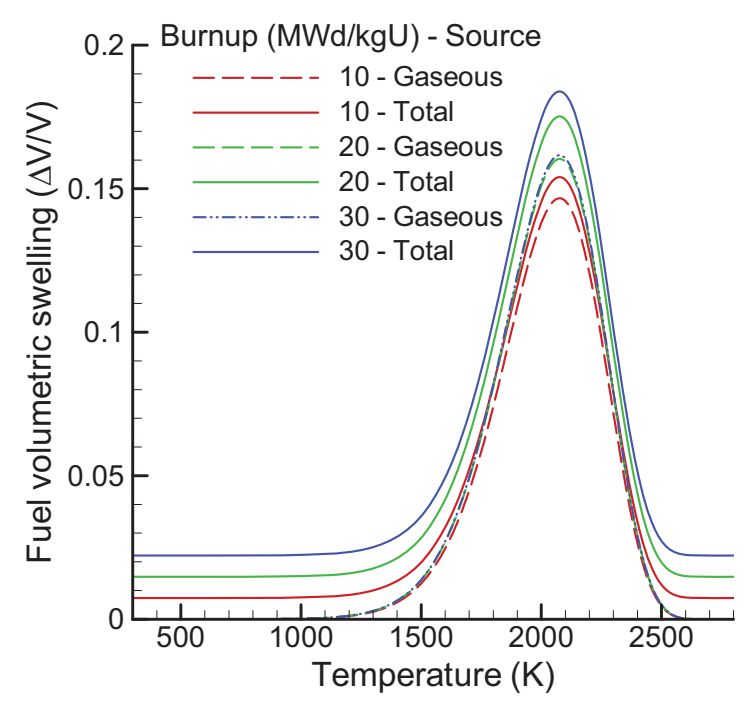

Figure 2 Gaseous and total fuel swelling as a function of temperature and burnup, based on MATPRO $^{13}$ correlations. 
$\mathrm{MWd} / \mathrm{kgU}$.

Fuel densification is computed using the ESCORE empirical model ${ }^{4}$ given by:

$$
\varepsilon_{D}=\Delta \rho_{0} e^{\frac{B u \ln (0.01)}{C_{D} B u_{D}}-1}
$$

where $\varepsilon_{\mathrm{D}}$ is the densification strain, $\Delta \rho_{0}$ is the total densification that can occur (given as a fraction of theoretical density), $\mathrm{Bu}$ is the burnup, $\mathrm{Bu}_{\mathrm{D}}$ is the burnup at which densification is complete, and $\mathrm{T}$ is the fuel temperature (in Celsius). For temperatures below $750 \mathrm{C}$ the parameter $C_{D}$ is given by $7.2-0.0086(T-25)$; above $750 \mathrm{C}$ it is 1.0 .

As a first step, fission gas release is modeled using a simple single-stage Booth-type diffusion model. The ANS5.4 formulation, as outlined in the $\mathrm{FALCON}^{4}$ theory manual, is implemented in a user subroutine which computes the fission gas produced and trapped at each material point. The difference is the gas released, which, after summing over all material points to obtain the total fission gas, is added to the gap/plenum region. The formulation uses a modified diffusion coefficient which is a function of temperature and burnup ${ }^{14}$. The ABAQUS implementation was verified by comparison to published curves of fission gas release versus burnup at constant fuel temperature $^{14}$. Note that the original ANS-5.4 formulation requires significant computer memory and processing time since, at each computational time-step (and material point), the gas release is a function of the production rate and diffusion coefficient at all prior time-steps. This issue has been circumvented in the FALCON code using an approximate recursion relation ${ }^{4}$, an approach which would be necessary in the current implementation for application to large problems. It is further noted that although a simple single-stage fission gas release model was chosen as a first step, there are no apparent obstacles preventing implementation of a more complex formulation such as the two-stage Forsberg-Massih ${ }^{15}$ model.

\section{II.C. Cladding Models}

Assuming Zircaloy as the clad material, models have been developed for thermal and irradiation creep and irradiation growth.

Secondary thermal creep of Zirconium alloys was recently thoroughly investigated by Hayes et al. ${ }^{16}$ and found to be well-described by a traditional power-law creep formulation. The specific equation implemented in the ABAQUS CREEP user subroutine is given by:

$$
\dot{\varepsilon}_{s s}=A_{0} e^{(-Q / R T)}\left(\sigma_{m} / G\right)^{n}
$$

where $\dot{\varepsilon}_{s s}$ is the effective thermal creep rate $(1 / \mathrm{s}), \sigma_{\mathrm{m}}$ is the effective (Mises) stress, $\mathrm{Q}$ is the activation energy
$(\mathrm{J} / \mathrm{mol}), \mathrm{R}$ is the universal gas constant $(\mathrm{J} / \mathrm{mol}-\mathrm{K})$, $\mathrm{T}$ is the temperature $(\mathrm{K}), \mathrm{G}$ is the shear modulus $(\mathrm{Pa})$, and $\mathrm{A}_{0}$ and $\mathrm{n}$ are material constants. For Zr-4, Hayes ${ }^{16}$ recommends a temperature dependent shear modulus given by $\mathrm{G}=$ $4.2519 \times 10^{10}-2.2185 \times 10^{7} \mathrm{~T}$.

Irradiation-induced creep of cladding materials is based on an empirical model developed by Hoppe ${ }^{17}$ which relates the creep rate to the current fast neutron flux and stress. The specific relation implemented is:

$$
\dot{\varepsilon}_{i r}=C_{0} \Phi^{C_{1}} \sigma^{C_{2}}
$$

where $\dot{\varepsilon}_{i r}$ is the effective irradiation creep rate $(1 / \mathrm{s}), \Phi$ is the fast neutron flux $\left(\mathrm{n} / \mathrm{m}^{2} \mathrm{~s}\right), \sigma_{\mathrm{m}}$ is the effective (Mises) stress (MPa), and $\mathrm{C}_{0}, \mathrm{C}_{1}$, and $\mathrm{C}_{2}$ are material constants.

Cladding elongation as a result of radiation-induced growth is included using the ESCORE empirical model ${ }^{4}$ given by:

$$
\varepsilon_{g}=A_{g}(\Phi t)^{n_{g}}
$$

where $\varepsilon_{g}$ is the irradiation growth strain, $\Phi t$ is the fast neutron fluence $\left(\mathrm{n} / \mathrm{cm}^{2}\right)$, and $\mathrm{A}_{\mathrm{g}}$ and $\mathrm{n}_{\mathrm{g}}$ are material constants that depend on the cladding metallurgical state. Axial elongation was implemented using the volumetric swelling capability in ABAQUS, but prescribed as anisotropic with swelling permitted in the axial direction only.

\section{II.C. Gap/Plenum Models}

Heat exchange across the fuel-clad gap is typically modeled using a relation such as:

$$
h_{\text {gap }}=h_{r}+h_{g}+h_{s}
$$

where $h_{\text {gap }}$ is the total conductance across the gap, $h_{r}$ is the radiant conductance, $h_{g}$ the gas conductance, and $h_{s}$ the increased conductance due to solid-solid contact. The radiant conductance was modeled using the standard gap radiation capability in ABAQUS and, for closely spaced surfaces, is dependent upon the surface emissivities and a viewfactor. A user subroutine was developed to include the remaining two conductance terms in Eqn. 7.

The gas conductance is described using the wellknown model proposed by Ross and Stoute ${ }^{18}$ and given by:

$$
h_{g}=\frac{k_{g}}{d_{g}+1.5\left(R_{f}+R_{c}\right)+g_{f}+g_{c}}
$$

where $\mathrm{k}_{\mathrm{g}}$ is the gas thermal conductivity, $\mathrm{d}_{\mathrm{g}}$ the gap width, $R_{f}$ and $R_{c}$ the surface roughness of the fuel and clad, respectively, and $g_{f}$ and $g_{c}$ the jump distances for the fuel and clad, respectively. The thermal conductivity of the gas mixture $\left(\mathrm{k}_{\mathrm{g}}\right)$ is computed as a function of the individual gas 
conductivities and their respective mole fractions, using the gas mixture rule described in detail in MATPRO ${ }^{13}$. The temperature-dependent conductivity of each gas component is expressed as a simple power law $\left(\mathrm{k}=\mathrm{A} \mathrm{T^{ \textrm {B } }}\right)$ and the respective mole fractions are computed based on the initial fill gas and all fission gas released from the fuel. As in Ref. 4, fission gas is assumed to be only xenon and krypton, with a $\mathrm{Xe} / \mathrm{Kr}$ ratio of 5.54. The local gap width $\left(d_{g}\right)$ is obtained from the mechanics model. Note that, for simplicity, the jump distance effect was not included in the current implementation.

The increased conductance due to solid-solid contact is described using the model given by Olander ${ }^{19}$ :

$$
h_{s}=C_{s} \frac{2 k_{f} k_{c}}{k_{f}+k_{c}} \frac{P_{c}}{\delta^{1 / 2} H}
$$

where $\mathrm{C}_{\mathrm{s}}$ is a constant (typically 1.0 ), $\mathrm{k}_{\mathrm{f}}$ and $\mathrm{k}_{\mathrm{c}}$ are the fuel and clad thermal conductivities, respectively, $\mathrm{P}_{\mathrm{c}}$ is the contact pressure (obtained form the contact model), $\delta$ is the average gas film thickness, and $\mathrm{H}$ is the Meyer hardness of the softer material.

It is emphasized that in the ABAQUS implementation, the gap heat transfer is tightly coupled to the mechanics model (via the gap width and contact pressure) and the fission gas release model (via the mixture gas thermal conductivity). This tight coupling results in smooth and rapid convergence of the nonlinear solution during gap closure, as will be shown below. The convergence rate of the ABAQUS Newton iteration was found to be strongly dependent upon accurate definition of the Jacobian terms (most significantly $\partial h_{g} / \partial d_{g}$ ) which, for Eqns. 8 and 9, are defined analytically in the gap user subroutine.

The plenum region and all gaps (both pellet/clad and pellet/pellet) are modeled using the fluid-filled cavity capability in ABAQUS. By defining surface elements on the boundary of the fluid cavity, the cavity volume is computed based on the evolving mechanics. The total fluid mass in the cavity is computed by simply adding the fission gas released from the fuel to the initial fill gas. The gas temperature is assumed to be uniform within the cavity and is related to the temperature of neighboring solid materials using sensors (one or many) placed at individual finite element nodes. The fluid pressure is computed assuming ideal gas behavior and applied to the entire boundary of the cavity. In this fashion, the gap pressure is fully coupled to the evolving solid mechanics.

\section{DEMONSTRATION PROBLEM AND RESULTS}

\section{III.A. Problem Description}

The various modeling capabilities described above are demonstrated using a $2 \mathrm{D}$ axisymmetric analysis of the upper section of a simplified fuel rod. The assumed geometry, materials, and boundary conditions are shown in Fig. 3. The problem includes two individual $\mathrm{UO}_{2}$ pellets, $\mathrm{Zr}-4$ cladding, an initial $80 \mu \mathrm{m}$ pellet-clad gap, and an open region to simulate the upper plenum. Although the fuel and cladding shapes are intentionally simplified in this demonstration problem, geometries of any complexity are possible with the $2 \mathrm{D}$ and $3 \mathrm{D}$ solid elements in ABAQUS. Note in Fig. 3 that a symmetry boundary (both mechanical and thermal) permits analysis of only the upper half of the bottom pellet. A convective boundary condition (assumed uniform) at the clad outer wall simulates heat transfer to the flowing coolant.

A typical computational mesh is shown in Fig. 4. Second order (quadratic) reduced-integration elements were used. For this simple demonstration problem, mesh resolution studies were not performed.

The assumed operating conditions, fuel and clad surface properties, and fuel density and densification conditions, are defined in Table I. Operating conditions typical of a PWR reactor are utilized. Note that, following

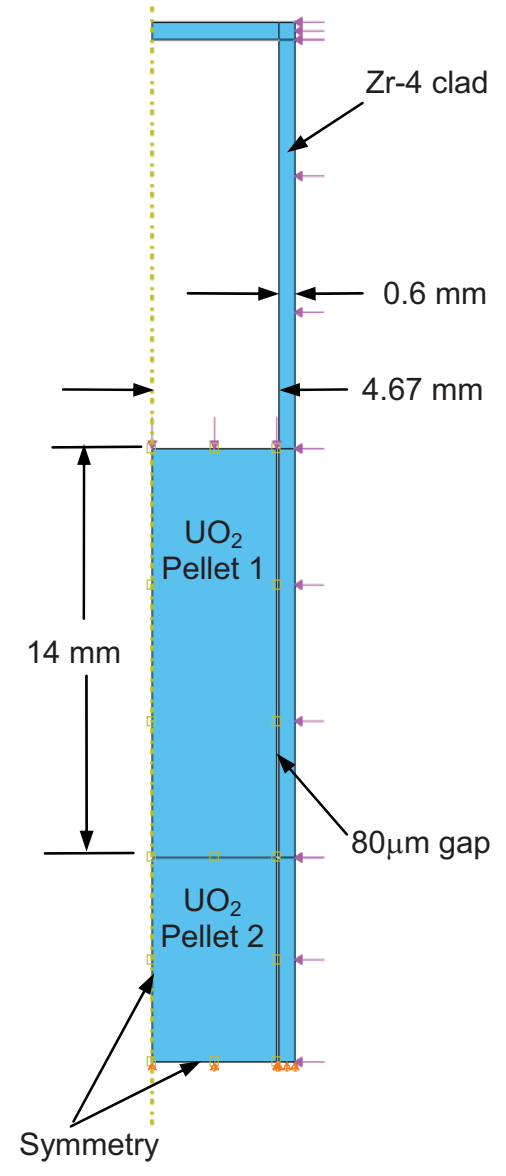

Figure 3 Assumed geometry, materials, and boundary conditions for the demonstration problem. 
TABLE I

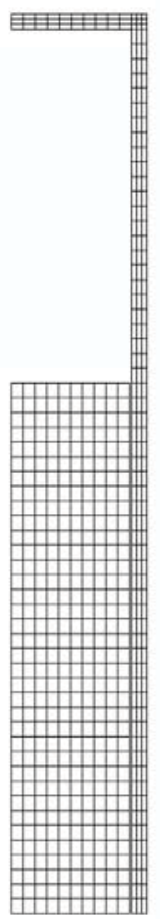

Figure 4 Typical computational mesh used for the demonstration problem.

contact, friction between the fuel and clad is included, assuming a constant friction factor of 0.25 .

Thermal properties for $\mathrm{UO}_{2}$ were specified via user subroutine, as described above. The $\mathrm{UO}_{2}$ Young's modulus, Poisson's ratio, and thermal expansion coefficient were assumed constant at $219 \mathrm{GPa}, 0.345,10.0$ x $10^{-6} \mathrm{~K}^{-1}$, respectively, as given in Ref. 19 .

Temperature dependent thermal, elastic, and plastic properties for $\mathrm{Zr}-4$ were taken from MATPRO ${ }^{13}$ Plasticity was computed assuming a von Mises yield condition and isotropic hardening. Anisotropic thermal expansion was included, using recommended values from MATPRO. ${ }^{13}$ Material constants for the thermal creep, irradiation creep, and irradiation growth of $\mathrm{Zr}-4$, as defined in Eqns. (4-6), are given in Table II.

As illustrated in Fig. 5, the analysis includes three time periods: an initial rise to power from ambient conditions, steady operation over roughly 4.75 years (to a burnup of $67 \mathrm{MWd} / \mathrm{kgU})$, and then a power ramp (50\% increase over 30 minutes) and $12 \mathrm{hr}$ hold.
Assumed operating conditions, fuel densification parameters, and fuel/clad surface properties

\begin{tabular}{|l|l|}
\hline Linear power (uniform) & $240 \mathrm{~W} / \mathrm{cm}$ \\
\hline Fast neutron flux & $5.0 \times 10^{17} \mathrm{n} / \mathrm{m}^{2} \mathrm{~s}$ \\
\hline Coolant pressure & $15.5 \mathrm{MPa}$ \\
\hline Coolant temperature (uniform) & $500 \mathrm{~K}$ \\
\hline Coolant convection coefficient & $7500 \mathrm{~W} / \mathrm{m}^{2} \mathrm{~K}$ \\
\hline Rod fill gas & helium \\
\hline Fill gas initial pressure & $2.5 \mathrm{MPa}$ \\
\hline Initial fuel density & $95 \%$ theoretical \\
\hline Fuel densification & $2 \%$ of theoretical \\
\hline Burnup at full densification & $5 \mathrm{MWd} / \mathrm{kgU}$ \\
\hline Fuel surface roughness & $2.0 \mu \mathrm{m}$ \\
\hline Clad surface roughness & $1.0 \mu \mathrm{m}$ \\
\hline Fuel emissivity & 0.8 \\
\hline Clad emissivity & 0.8 \\
\hline Clad Meyer hardness & $1.0 \mathrm{GPa}$ \\
\hline Pellet-clad friction factor & 0.25 \\
\hline
\end{tabular}

TABLE II

Material constants for the thermal creep, irradiation creep, and irradiation growth of Zr-4

\begin{tabular}{|c|c|c|}
\hline $\begin{array}{c}\text { Material } \\
\text { constant }\end{array}$ & Value & Reference \\
\hline \multicolumn{3}{|c|}{ Thermal Creep } \\
\hline $\mathrm{A}_{0}$ & $3.14 \times 10^{24} \mathrm{~s}^{-1}$ & $*$ \\
\hline $\mathrm{Q}$ & $270,000 \mathrm{~J} / \mathrm{mol}$ & 16 \\
\hline $\mathrm{n}$ & 5 & 16 \\
\hline \multicolumn{3}{|c|}{ Irradiation Creep } \\
\hline $\mathrm{C}_{0}$ & $9.881 \times 10^{-28}$ & 20 \\
\hline $\mathrm{C}_{1}$ & 0.85 & 20 \\
\hline $\mathrm{C}_{2}$ & 1.0 & 20 \\
\hline \multicolumn{3}{|c|}{ Irradiation Growth } \\
\hline $\mathrm{A}_{\mathrm{g}}$ & $3 \times 10^{-20}$ & 4 \\
\hline $\mathrm{n}_{\mathrm{g}}$ & 0.794 & 4 \\
\hline
\end{tabular}

* approximated based on data in Ref 16 


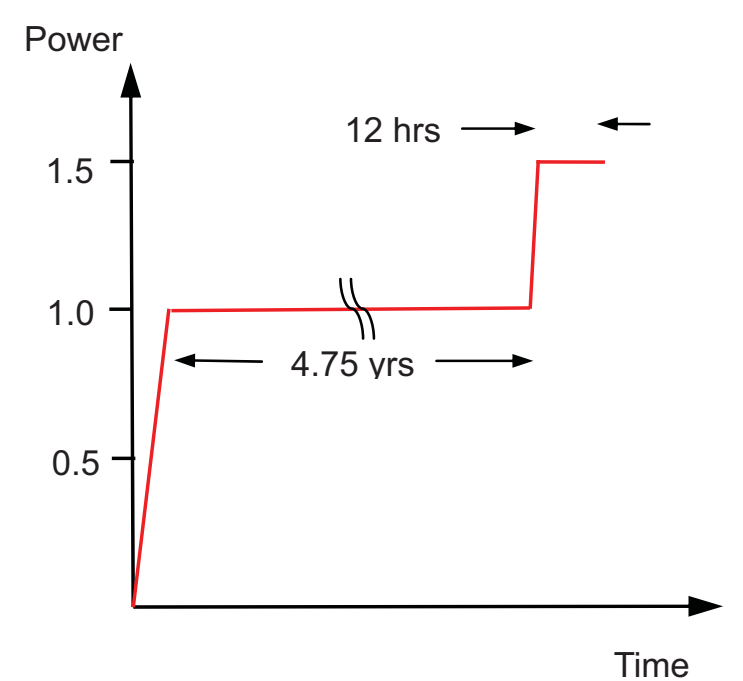

Figure 5 Assumed power history showing start-up, steady operation, and a final power ramp. The power factor is multiplied by the linear power given in Table I.

\section{III.B. Results}

A variety of computational results are provided during both steady operation and the final power-ramp and hold.

Figure 6 shows the predicted temperature histories at the fuel centerline and surface, and at the inner cladding wall, during steady operation. Following initial power-up the fuel centerline temperature is approximately $1320 \mathrm{~K}$, but then rises during early irradiation, due to an increase in fuel-clad gap as a result of fuel densification. Once

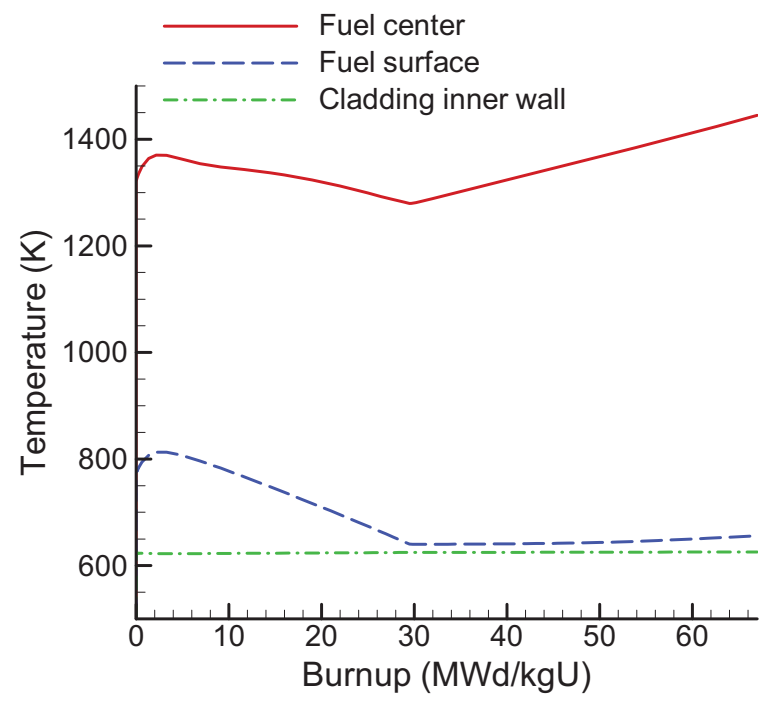

Figure 6 Predicted temperature versus burnup at the center and surface of the fuel, and at the clad inner wall. densification is complete, fuel swelling and continuous clad creep-down results in continuous gap reduction and a corresponding drop in the centerline temperature. For the location plotted, gap closure occurs at a burnup of approximately $30 \mathrm{MWd} / \mathrm{kgU}$, after which both the fuel centerline and surface temperatures gradually rise due to decreasing $\mathrm{UO}_{2}$ conductivity with burnup.

The 2D axisymmetric model permits an in-depth view of the evolving temperature and stress fields at the so called "triple-point", where the ends of two adjacent pellets contact the cladding. Figure 7 is a sequence of temperature contour plots, showing the predicted local temperature field during gap closure. Early in fuel life, a significant thermal gradient exists across the gap. The gap conductance increases rapidly as contact approaches, resulting in a significant drop in the fuel temperature at the interface. Once full contact is established, only a small thermal gradient exists between the fuel and clad materials. The temperature and displacement results demonstrate the importance of fully-coupled thermomechanics as the gap narrows and contact occurs. Not only does the temperature effect the displacements, but localized displacements clearly have a strong effect on the temperature.

Figure 8 shows a similar sequence of contour plots, however the focus here is on the axial stress in the cladding. Prior to contact, the axial stress is small in magnitude, and is tensile due to gas pressure in the plenum. Initial contact at the triple-point results in localized bending of the clad and axial stresses ranging from small compressive values at the inner wall to significant tension at the outer wall. Once contact occurs along the full length of the pellet and the fuel and clad are mechanically coupled via friction, fuel swelling results in clad axial elongation and significant axial tensile stress across the full clad thickness. The results demonstrate the importance of multidimensional analysis at the triple-point region.

The predicted gap width versus burnup, at both the pellet end and axial centerline, is shown in Fig. 9. The gap drops roughly in half (from 80 to $40 \mu \mathrm{m}$ ) during the initial heat-up, as indicated at zero burnup. As expected due to the hourglass shape of the pellet, gap closure occurs at the pellet ends prior to closure at the pellet axial centerline. Symbols included on each curve and placed at every second computational time increment, provide a visual interpretation of the time step evolution during the calculation. For this simulation, ABAQUS was permitted to automatically control the time increment based on its error control algorithms. Note that the time step gradually increases during gap closure until near final closure, when much smaller increments are needed for convergence. Note that the fully coupled thermomechanics algorithm results in very smooth closure, even though significant nonlinear behavior (e. g., gap gas thermal conductivity reduction with fission gas release) is included. 

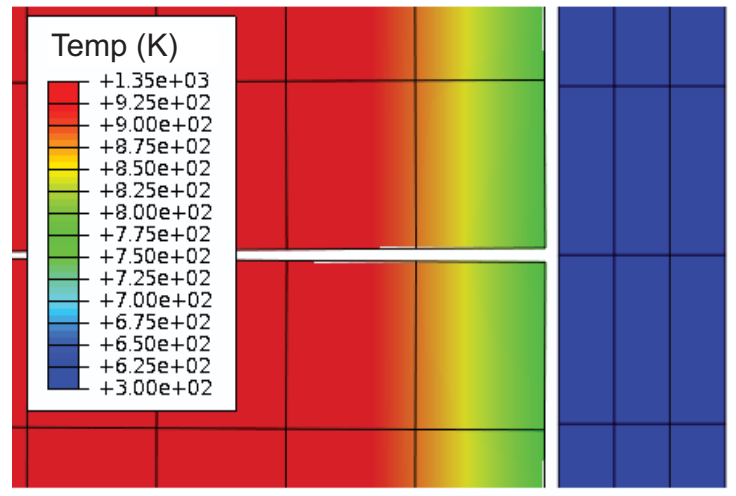

a.) $\mathrm{Bu}=6.9 \mathrm{MWd} / \mathrm{kgU}$

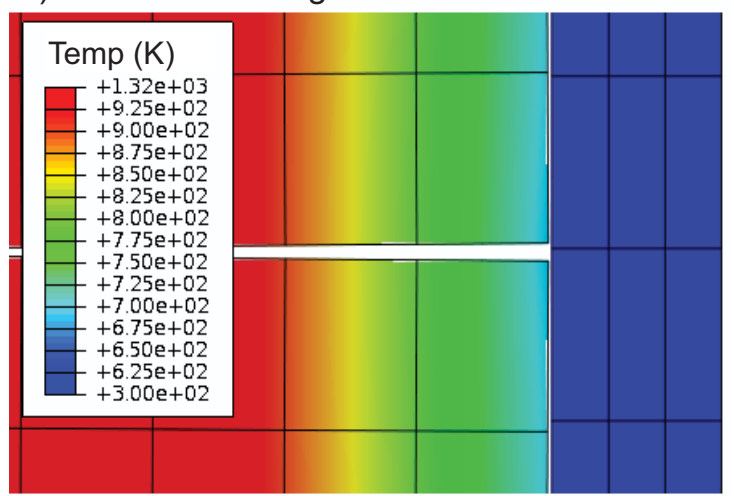

b.) $\mathrm{Bu}=21.0 \mathrm{MWd} / \mathrm{kgU}$

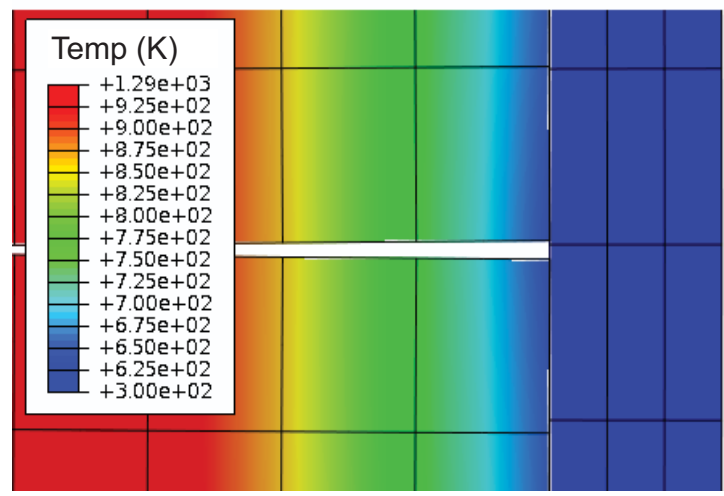

c.) $\mathrm{Bu}=28.3 \mathrm{MWd} / \mathrm{kgU}$

Figure 7 Temperature contours at the junction of two pellets and the cladding, at various stages of gap closure.

Figure 10 displays the predicted total fission gas release (FGR) and the pressure and volume of the gap/plenum (cavity) region, as a function of burnup, during steady operation. The pressure and volume are normalized using initial (cold) and final (end of power ramp) values, as defined in the plot legend. Based on the simple single-stage diffusion model, significant fission gas release is not observed until the burnup exceeds 40 $\mathrm{MWd} / \mathrm{kgU}$. The cavity pressure roughly doubles at startup due to an increase in gas temperature. The pressure then increases as a result of released fission gas, as expected.

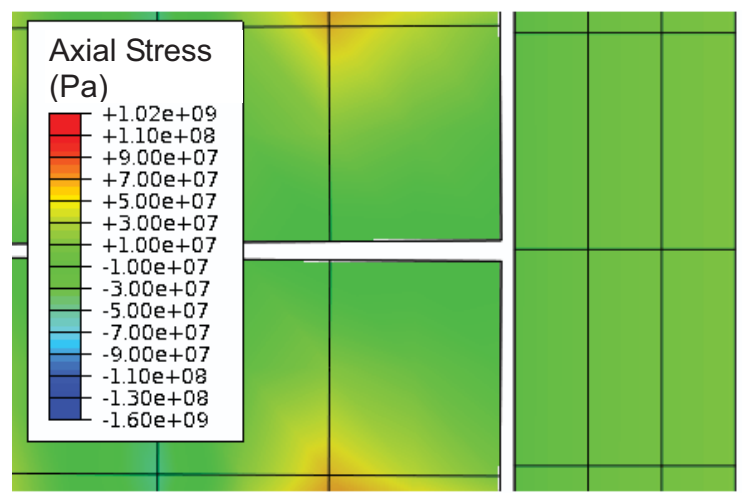

a.) $\mathrm{Bu}=11.6 \mathrm{MWd} / \mathrm{kgU}$

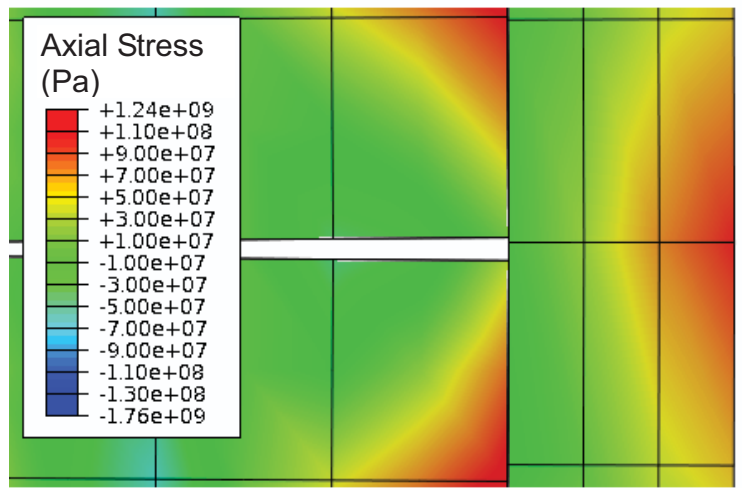

b.) $\mathrm{Bu}=34.4 \mathrm{MWd} / \mathrm{kgU}$

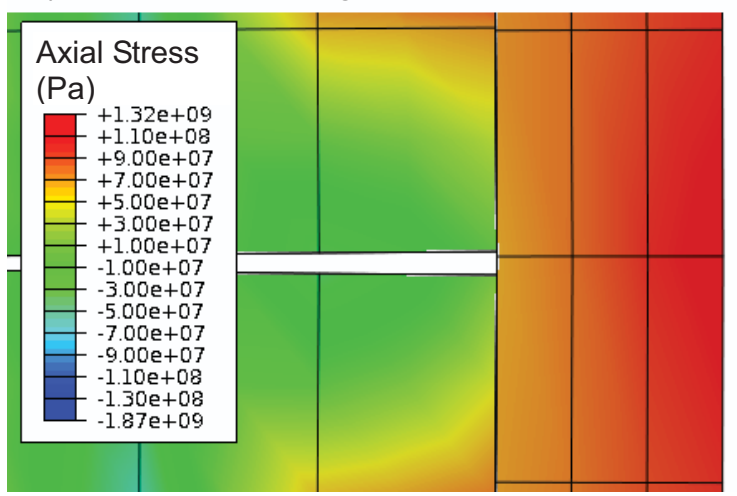

c.) $\mathrm{Bu}=50.0 \mathrm{MWd} / \mathrm{kgU}$

Figure 8 Axial stress contours at the junction of two pellets and the cladding, at various stages of gap closure.

The cavity volume is initially decreased due to fuel heating, but then increases during early irradiation due to fuel densification (as was observed in Fig. 9). Once densification is complete (at $5 \mathrm{MWd} / \mathrm{kgU}$ ) the volume continually decreases due to fuel swelling and clad creepdown, until gap closure. Note in Fig. 10 that the predicted FGR is not precisely zero at startup. The ANS-5.4 FGR formulation includes an analytical solution to the diffusion equation in terms of an infinite series. The small early error in FGR is the result of using a finite number of terms in the series, and can be reduced by including additional terms. 


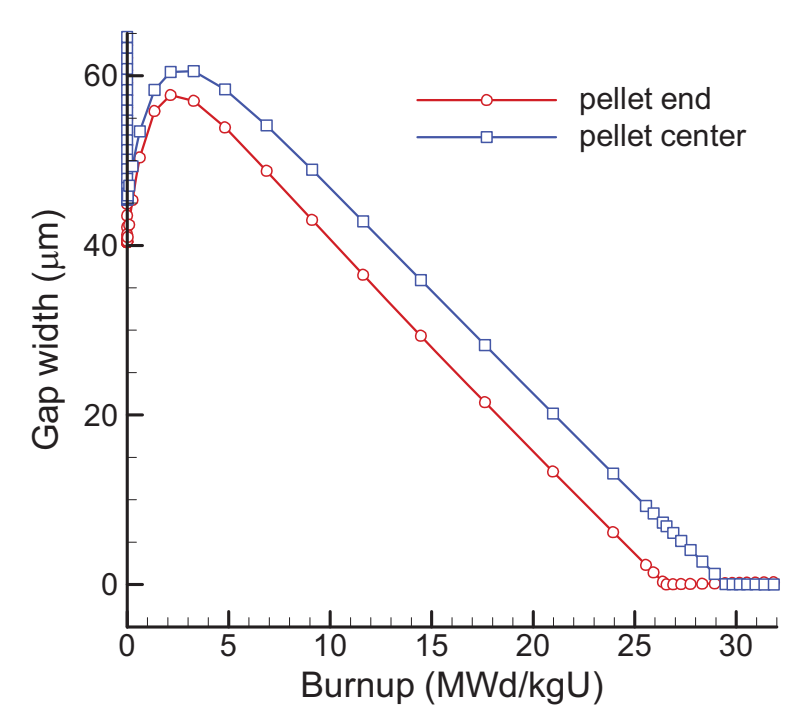

Figure 9 Gap closure versus burnup at the end and center of a fuel pellet.

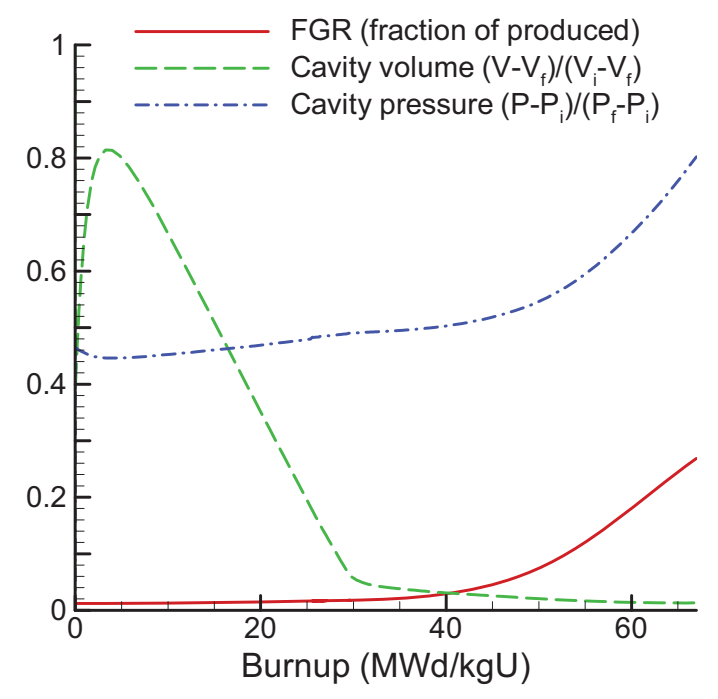

Figure 10 Fission gas release (FGR), cavity volume, and cavity pressure versus burnup during steady operation. The cavity includes the plenum region and any gaps within the rod. The volume and pressure are normalized as indicated in the legend.

Fuel and clad behavior during the power-ramp and hold are shown in Figs. 11 and 12. Figure 11 displays time histories of the predicted fuel centerline and surface temperature, and total fission gas release. The large and rapid increase in fuel temperature results in a significant release of trapped fission gases. Figure 12 shows the equivalent creep and plastic strain, and Mises stress, plotted along the outer wall of the cladding before and

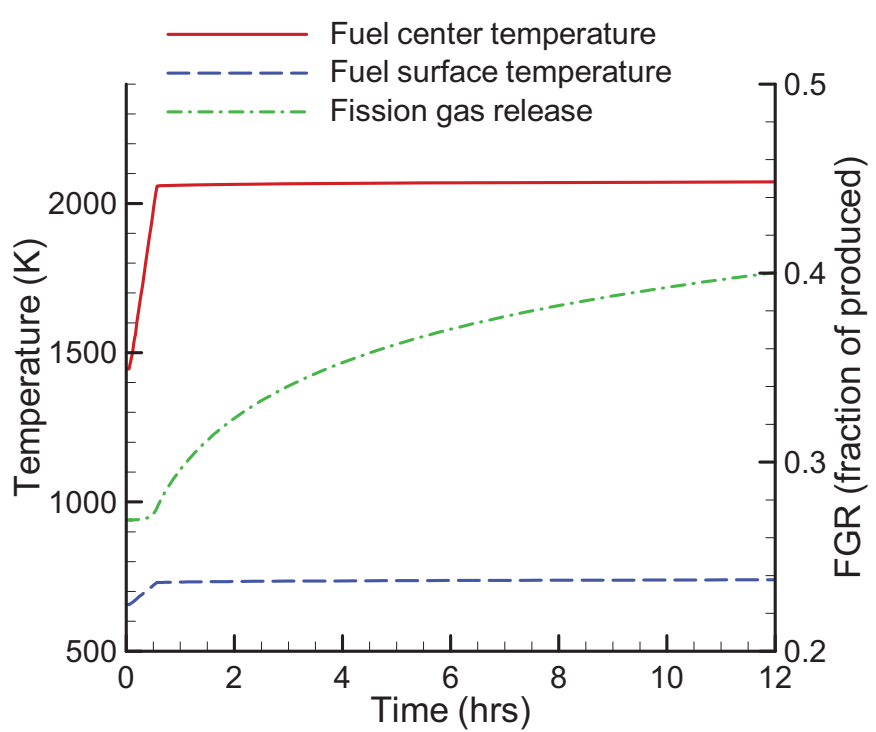

Figure 11 Predicted fuel centerline and surface temperature, and total fission gas release, during the power-ramp and hold step.

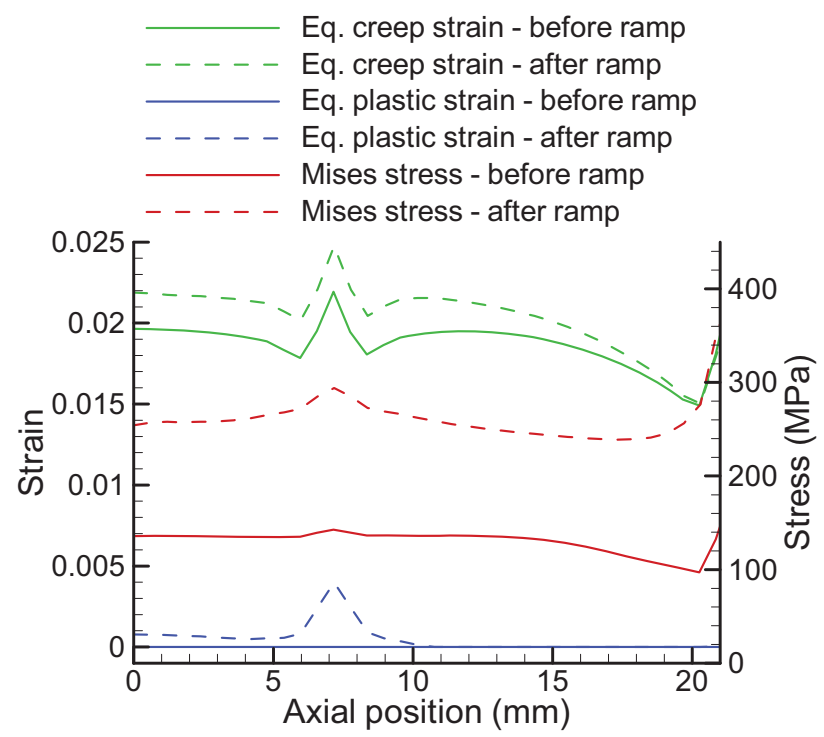

Figure 12 Predicted equivalent creep strain, equivalent plastic strain, and Mises stress as a function of axial length along the cladding outer wall, both before and after the power-ramp and hold step.

after the power-ramp and hold step. Note that prior to the ramp, all inelastic cladding deformation is due to thermal and irradiation creep. A 50\% power ramp results in a large increase (more than double) in the cladding Mises stress, exceeding the yield strength in the triple-point region, and resulting in localized plasticity. Continued thermal creep in the clad during the $12 \mathrm{hr}$ hold is significant, due to the increased clad temperature. 


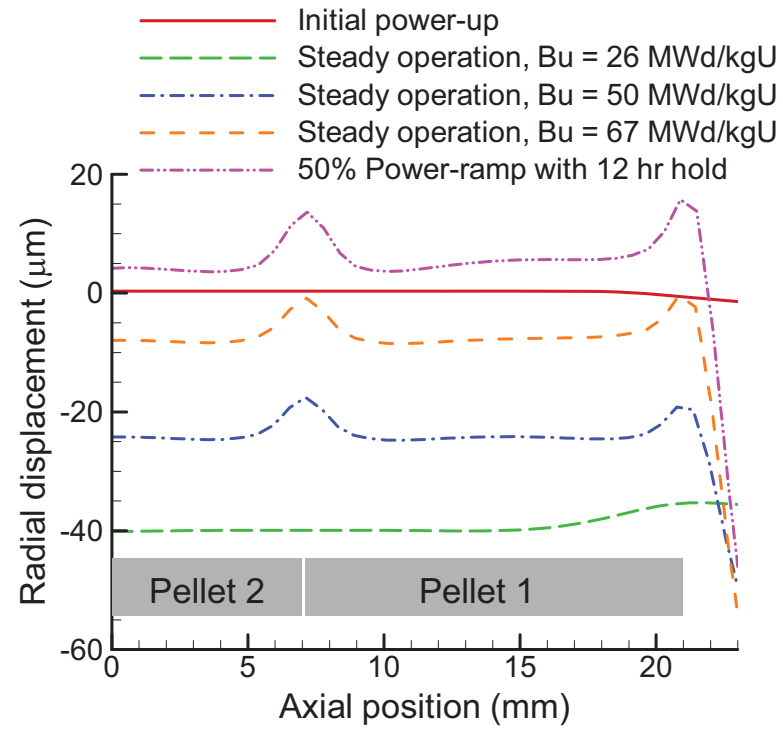

Figure 13 Radial displacement of the cladding outer wall at various times in fuel life.

Figure 13 is a plot of the clad outer wall radial displacement, versus axial length, at various times in the fuel life. A schematic showing the orientation of the two pellets considered in the model is included. The plot shows an initial nearly uniform inward displacement, resulting from creep-down during steady operation. This displacement is slightly reduced at the end of Pellet 1 due to lower clad temperatures in this region. Following gap closure, the clad reverses direction as indicated by the displacement curve at $50 \mathrm{MWd} / \mathrm{kgU}$. The local peak in clad displacement at the pellet-pellet interface results from the hourglass shape of the fuel pellets. At the end of steady operation the clad is nearly back to its original diameter, but then enlarges significantly during the powerramp and hold step. The commonly observed "bamboo" profile along the clad length is obvious. Figure 13 again demonstrates the importance of a multidimensional treatment in the triple-point region.

An important final point is that the implicit numerics and error-based time step control in ABAQUS permits time step sizes ranging from a few seconds during the start-up and power-ramp steps, to greater than 40 days during steady operation. The code can thus easily accommodate combined steady and transient reactor operations. Note that ABAQUS is also capable of multiprocessor computations, which becomes important for either full-rod discrete-pellet 2D simulations or $3 \mathrm{D}$ analysis.

\section{CONCLUSIONS}

A powerful multidimensional fuels performance capability, applicable to both steady and transient fuel behavior, has been developed based on enhancements to the ABAQUS general-purpose commercially available thermomechanics code. Enhanced capabilities applicable to fuel performance modeling include:

- $\mathrm{UO}_{2}$ temperature and burnup dependent thermal properties

- $\quad$ solid and gaseous fission product swelling

- fuel densification

- fission gas release

- cladding thermal and irradiation creep

- cladding irradiation growth

- gap heat transfer

- gap/plenum gas behavior during irradiation

The various modeling capabilities are demonstrated using a 2D axisymmetric analysis of the upper section of a simplified multi-pellet fuel rod, during both steady and transient operation. Computational results demonstrate the importance of a multidimensional fully-coupled thermomechanics treatment. Interestingly, many of the inherent deficiencies in existing fuel performance codes (e.g., 1D thermomechanics, loose thermo-mechanical coupling, separate steady and transient analysis, cumbersome pre- and post-processing) are, in fact, ABAQUS strengths.

Future development efforts will include implementation of a smeared-cracking model to account for fuel fracture and inclusion of a more realistic two-stage fission gas release model. Most importantly, comparisons to a variety of experimental data will be made.

\section{ACKNOWLEDGMENTS}

Work supported through the INL Laboratory Directed Research \& Development (LDRD) Program under DOE Idaho Operations Office Contract DE-AC07-05ID14517.

\section{REFERENCES}

1. G. A. Berna, C. E. Beyer, K. L. Davis, and D. D. Lansing, "FRAPCON-3: A Computer Code for the Calculation of Steady-State, Thermal-Mechanical Behavior of Oxide Fuel Rods for High Burnup", NUREG/CR-6534 (1997). 
2. P. Van Uffelen, "Towards Nuclear Fuel Modeling in the Various Reactor Types Across Europe with TRANSURANUS", Proc. Enlargement and Integration Workshop, Prague, Czech Republic, June 23-24 (2005).

3. W. J. Kilgour, J. A. Turnbull, R. J. White, A. J. Bull, P. A. Jackson, and I. D. Palmer, "Capabilities and Validation of the ENIGMA Fuel Performance Code", Proc. ENS Meeting on LWR Fuel Performance, Avignon, France (1992).

4. Y. Rashid, R. Dunham, and R. Montgomery, Fuel Analysis and Licensing Code: FALCON MOD01, EPRI Report 1011308, December (2004).

5. F. Bentejac and N. Hourdequin, "TOUTATIS: An Application of the CAST3M Finite Element Code for PCI Three-Dimensional Modeling", Proc. Pellet-clad Interaction in Water Reactor Fuels, Aix-en-Provence, France, March 9-11 (2004).

6. G. Thouvenin, B. Michel, J. Sercombe, and D. Plancq, "Multidimensional Modeling of a Ramp Test with the PWR Fuel Performance Code ALCYONE", Proc. 2007 Int. LWR Fuel Performance Meeting, San Francisco, CA, Sept. 30-Oct. 3 (2007).

7. Proc. Pellet-clad Interaction in Water Reactor Fuels, Aix-en-Provence, France, March 9-11 (2004).

8. C. Newman, G. Gaston, and G. Hansen, "Computational Foundations for Reactor Fuel Performance Modeling", ANS Int. Conf. on Mathematics, Computational Methods \& Reactor Physics, Saratoga Springs, New York, May 3-7 (2009).

9. C. Newman, G. Hansen, D. Gaston, "Three Dimensional Coupled Simulation of Thermomechanics, Heat, and Oxygen Diffusion in $\mathrm{UO}_{2}$ Nuclear Fuel Rods", J. Nuc. Mat., in press.

10. ABAQUS Software, SIMULIA, Rising Sun Mills, 166 Valley Street, Providence, RI.

11. J. K. Fink, "Thermophysical Properties of Uranium Dioxide", J. Nuc. Mat, 279, 1 (2000).

12. P. G. Lucuta, H. Matzke, and I. J. Hastings, "A Pragmatic Approach to Modeling Thermal Conductivity of Irradiated $\mathrm{UO}_{2}$ Fuel: Review and Recommendations", J. Nuc. Mat., 232, 166 (1996).
13. C. M. Allison, et al., "SCDAP/RELAP5/MOD3.1 Code Manual Volume IV: MATPRO", NUREG/CR6150 (1993).

14. "Background and Derivation of ANS-5.4 Standard Fission Product Release Model", NUREG/CR-2507 (1982).

15. K. Forsberg and A. R. Massih, "Diffusion Theory of Fission Gas Migration in Irradiated Nuclear Fuel $\mathrm{UO}_{2}$ ", J. Nuc. Mat., 135, 140 (1985).

16. T. A. Hayes and M. E. Kassner, "Creep of Zirconium and Zirconium Alloys", Met. and Mat. Trans., 37A, 2389 (2006).

17. N. E. Hoope, "Engineering Model for Zircaloy Creep and Growth", Proc. ANS-ENS International Topical Meeting on LWR Fuel Performance, Avignon, France, April 21-24 (1991).

18. A. M. Ross and R. L. Stoute, "Heat Transfer Coefficient between $\mathrm{UO}_{2}$ and Zircaloy-2, CRFD-1075 (1962).

19. D. R. Olander, Fundamental Aspects of Nuclear Reactor Fuel Elements, Ch. 10 and 16, National Technical Information Service, Springfield, VA (1978).

20. M. Limback and T. Anderson, "A Model for Analysis of the Effect of Final Annealing on the In- and Out-ofReactor Creep Behavior of Zircaloy Cladding", Zirconium in the Nuclear Industry: Eleventh International Symposium, ASTM STP 1295 (1996). 